\title{
OJS OPEN

\section{A FORMAÇÃO INICIAL E CONTINUADA DE PROFESSORES DE GEOGRAFIA A PARTIR DA REFLEXÃO DOCENTE}

\author{
Juanice Pereira Santos ${ }^{1}$ Maria Solange Melo de Sousa ${ }^{2}$ \\ ${ }^{1}$ Doutoranda em Geografia, Universidade de Brasília - UnB. Contato:juanice.ahss@yahoo.com.br - ORCID iD: \\ https://orcid.org/0000-0002-6411-0669 \\ ${ }^{2}$ Doutoranda em Geografia, Universidade de Brasília - UnB. Contato: sollangemello@uol.com.br - ORCID iD: \\ https://orcid.org/0000-0002-4362-7845
}

Artigo recebido em 07/04/2020 e aceito em 20/05/2020

\begin{abstract}
RESUMO
O artigo é resultado de discussões feitas com docentes do Grupo de Pesquisa, Ensino, Aprendizagem e Formação de Professores (GEAF - UNB) ocorridas nas reuniões de estudo, no ano de 2019. O texto analisa a atuação do professor de Geografia em sala de aula, no que diz respeito à formação inicial e continuada, à deficiência dos saberes e das aprendizagens e o reflexo de tais fragilidades nas experiências vivenciadas no cotidiano escolar. O aporte teórico baseouse em documentos científicos de ensino de Geografia e Educação, reflexões de diferentes autores: Cavalcanti (2017); Cunha (2010); Nóvoa (1992; 2004); Pimenta (2012); Shulman (2005); leituras e discussões em grupo; coleta e registro de relatos e entrevistas dos professores membros do GEAF. Ao final da pesquisa, há considerações quanto às principais fragilidades no processo educativo que interferem na prática pedagógica do professor de Geografia. O texto também apontou a importância da formação inicial e continuada no sentido de qualificar e transformar as ações docentes em sala de aula.
\end{abstract}

Palavras-chave: Formação; Geografia; Professor.

\section{THE INITIAL AND CONTINUING TRAINING OF GEOGRAPHY TEACHERS FROM THE TEACHING REFLECTION}

\begin{abstract}
The article is the result of discussions with teachers of the Research Group, Teaching, Learning and Teacher Training (GEAF - UNB) that took place at the study meetings in 2019. The text analyzes the performance of the geography teacher in the classroom, with regard to initial and continuing education, the deficiency of knowledge and learning and the reflection of such weaknesses in the experiences experienced in the school routine. The theoretical contribution was based on scientific documents of geography and education teaching, reflections of different authors: Cavalcanti (2017); Cunha (2010); Nóvoa (1992; 2004); Pimenta (2012); Shulman (2005); group readings and discussions; collection and recording of reports and interviews of geaf member teachers. At the end of the research, there are considerations regarding the main weaknesses in the educational process that interfere in the pedagogical practice of the geography teacher. The text also pointed out the importance of initial and continued training in order to qualify and transform teaching actions in the classroom.
\end{abstract}


Keywords: Training; Geography; Teacher.

\title{
LA FORMACIÓN INICIAL Y CONTINUA DE PROFESORES DE GEOGRAFÍA DE LA REFLEXIÓN DEL PROFESORADO
}

\begin{abstract}
RESUMEN
El artículo es el resultado de las discusiones realizadas con profesores del Grupo de Investigación, Enseñanza, Aprendizaje y Formación del Profesorado (GEAF - UNB) que ocurrieron en las reuniones de estudio de 2019. El texto analiza el rendimiento del profesor de geografía en el aula, con respecto a la educación inicial y continua, la deficiencia de conocimiento y aprendizaje y el reflejo de tales debilidades en las experiencias experimentadas en la rutina escolar. La contribución teórica se basó en documentos científicos de geografía y enseñanza de la educación, reflexiones de diferentes autores: Cavalcanti (2017); Cunha (2010); Nóvoa (1992; 2004); Pimienta (2012); Shulman (2005); lecturas y debates grupales; recopilación y registro de informes y entrevistas de maestros miembros de geaf. Al final de la investigación, hay consideraciones con respecto a las principales debilidades en el proceso educativo que interfieren en la práctica pedagógica del profesor de geografía. El texto también señalaba la importancia de la educación inicial y continua para calificar y transformar las acciones docentes en el aula.
\end{abstract}

Palabras clave: Entrenamiento; Geografía; Profesor.

\section{INTRODUÇÃO}

A atuação docente tem se configurado como um desafio para o professor de Geografia, alvo de críticas diante das transformações no cenário brasileiro. E, nesse sentido, não se pode perder de vista a sua formação profissional, pois esta atividade é peculiar aos saberes que envolvem a formação e fundamenta sua prática de ensino, o tema é relevante em todas as discussões e estudos. Tanto a formação inicial quanto a continuada são requisitos para qualificar o trabalho docente, difundindo ideias e favorecendo a atualização constante. Em função das mudanças nos conhecimentos decorrentes das novas tecnologias e das transformações ocorridas no mundo do trabalho, a formação inicial e continuada tem a finalidade de favorecer a formação dos professores para a educação básica diante de novos paradigmas.

Diante do exposto, as instituições de ensino superior precisam aperfeiçoar os cursos de licenciatura, pois cooperam para a formação humana, intelectual e pedagógica dos docentes para a geração futura. Assim, os cursos de graduação de Geografia necessitam avançar na formação inicial dos futuros professores no que diz respeito à tripla dimensão dos saberes: o saber, o saber fazer e o saber ser (NÓVOA, 2004), para formar profissionais capazes de desenvolver práticas pedagógicas que conduzam à construção dos conhecimentos geográficos e favoreça à aprendizagem significativa dos alunos. 
A formação do professor pode estar relacionada às deficiências do ensino de Geografia no que diz respeito a construção de conceitos, a compreensão dos conteúdos geográficos e a não visão contextualizada do espaço vivido com o conteúdo de geografia trabalhado em sala de aula. Além disso, há carência de ações pedagógicas fora do ambiente escolar.

A partir do contexto apresentado, o objetivo do artigo é analisar a importância da formação inicial e da formação continuada para fortalecer a prática pedagógica dos professores de Geografia. Assim, pergunta-se: qual a avaliação do professor de geografia em relação à formação inicial? A formação inicial do professor de Geografia é suficiente para a promoção de boas práticas pedagógicas em sala de aula? Quais as dificuldades que ele enfrenta cotidianamente para desenvolver a sua prática pedagógica? Há sentimento de identidade do professor em relação à sua profissão? Tais questionamentos instigam discussões relacionados ao trabalho do professor de Geografia e podem contribuir no entendimento quanto à importância do bom desempenho desse profissional em sala de aula, a partir da formação inicial e continuada.

Nesta perspectiva, construiu-se o presente texto decorrente dos estudos de artigos, dissertações e teses, das discussões do Grupo de Pesquisa, Ensino, Aprendizagem e Formação de Professores (GEAF-UNB) e das análises dos relatos e entrevistas dos docentes. Trata-se de um estudo que busca maior reflexão sobre a formação inicial e a formação continuada na questão dos saberes pedagógico e do conhecimento e nas práticas cotidianas do professor ao trabalhar com a Geografia escolar.

A metodologia aplicada é pautada na pesquisa qualitativa. $\mathrm{O}$ tipo de abordagem qualitativa não se baseia em dados matemáticos ou estatísticos. Logo:

\footnotetext{
Podemos partir do princípio de que a pesquisa qualitativa é aquela que trabalha predominantemente com dados qualitativos, isto é, a informação coletada pelo pesquisador não é expressa em números, ou então os números e as conclusões neles baseadas representam um papel menor na análise (DALFOVO; LANA; SILVEIRA, 2008, p. 9).
}

A parte teórica da pesquisa utilizou-se da análise bibliográfica e documental. No decorrer da construção do artigo foi feita a análise do material bibliográfico e, também, de documentos relativo à formação inicial e continuada do professor de Geografia da educação básica do Distrito Federal. O trabalho investigativo utilizou-se da observação participante uma vez que as pesquisadoras têm atuação real no grupo de estudos e são professoras da rede pública de ensino. Segundo Bauer e Gaskell (2017, p. 72) 
Na observação participante, o pesquisador está mais aberto a uma maior amplitude e profundidade de informação, é capaz de triangular diferentes impressões e observações, e consegue conferir discrepâncias emergentes no decurso do trabalho de pesquisa.

Por fim, analisou-se os dados obtidos nos relatos e nas entrevistas individuais dos 14 professores membros do GEAF- UnB, no período de junho a dezembro de 2018. Durante as reuniões semanais o grupo estudou teses, dissertações acadêmicas e artigos científicos com temáticas relacionadas à formação e aos saberes docentes, às práticas pedagógicas e aos conhecimentos geográficos, com a efetiva participação das pesquisadoras. Os referenciais teóricos foram fundamentais no processo de compreensão das realidades estudadas e essenciais para se alcançar os resultados apresentados no artigo.

Os registros realizados durantes os encontros e as discussões do grupo de pesquisa abordam formação docente, pontuando o desempenho, os saberes, a prática e a metodologia desenvolvida em sala de aula por esses profissionais, considerando ainda a identidade profissional.

$\mathrm{O}$ artigo foi desenvolvido em quatro partes: na primeira parte a discussão teve como foco a importância da formação docente. Nela, analisou-se os relatos e os depoimentos coletados dos professores membros do GEAF-UNB; na segunda parte, apresentou-se as contribuições dos estudos, discussões e reflexões feitas em grupo para as práticas docentes nas aulas de Geografia; na terceira parte, é descrito os resultados da pesquisa e, por fim, as considerações finais referentes ao processo de desenvolvimento, discussões e análise do objeto pesquisado.

\section{A IMPORTÂNCIA DA FORMAÇÃO DOCENTE}

A formação docente é um assunto muito debatido no cenário educacional, uma vez que é marcado pelas constantes mudanças ocorridas no contexto social e no cotidiano escolar, provocando assim alterações nas relações entre professores e alunos. Diante dessa realidade, em que as mudanças são constantes, faz-se necessário repensar formas e possibilidades do fazer docente.

Desse modo, os processos formativos que legitimam a profissionalização do professor tornam-se objetos de estudo. Alguns dos autores dos textos estudados Cavalcanti (2017); Cunha (2010); Nóvoa (1992; 2004), Pimenta (2012) e Shulman (2005), partem do pressuposto de que a identidade do professor de Geografia está vinculada à sua formação docente, e, as instituições de 
nível superior nas quais eles obtiveram a formação inicial tem papel relevante, tanto na identidade quanto no desempenho profissional. A formação inicial com qualidade pode fomentar o profissional com viés de pesquisador, na qual o estudo é prática recorrente no exercício da docência e estreitar a identificação com a carreira, desenvolvendo assim potencialidades e habilidades que se manifestam na prática pedagógica em sala de aula.

Segundo Cunha (2010), abordar o tema da formação profissional dos professores assume cada vez maior complexidade no contexto atual. Um dos fatores desta complexidade é porque a sociedade atribuí responsabilidades crescentes à educação escolarizada e aos professores em todos os níveis do ensino. As atribuições são decorrentes das mudanças no mundo do trabalho, da revolução midiática e da alteração da estrutura na organização familiar. Em meio a diversas mudanças, cabe ao profissional da educação aperfeiçoar-se para poder enfrentar tamanhos desafios.

$\mathrm{Na}$ formação inicial têm-se a possibilidade da aquisição dos saberes científicos e pedagógicos, porém há dificuldades para desenvolvê-los na prática. Os autores Piconez (1991) e Pimenta (2012) argumentam que os cursos de formação inicial de docência, devem criar o currículo formal alinhando conteúdos, atividades e estágios que sejam coerentes com a realidade das escolas, o objetivo é captar as contradições presentes na prática social de educar e, assim, contribuir para gestar no profissional docente uma nova identidade.

De acordo com a LDB/1996 (Lei $n^{\circ}$. 9394/96) no Capítulo IV, que trata da educação superior, no Art. 43, a educação superior tem por finalidade, § VIII:

Atuar em favor da universalização e do aprimoramento da educação básica, mediante a formação e a capacitação de profissionais, a realização de pesquisas pedagógicas e o desenvolvimento de atividades de extensão que aproximem os dois níveis escolares. (Incluído pela Lei no 13.174 , de 2015).

Nesse viés, Silva e Barbosa (2019, p.147) enfatiza:

\begin{abstract}
A universidade precisa tomar a responsabilidade da continuidade na formação do educador de modo a propiciar elementos necessários para que os professores se libertem das "amarras" impostas pelas orientações políticas externas e, a partir de um trabalho coletivo, construam uma "proposta de formação continuada" consistente que atenda ao novo cenário de sociedade contemporânea.
\end{abstract}

Corroborando com as ideais dos autores, os relatos dos professores podem elencar algumas questões para reflexão sobre a formação inicial, são elas: considerar importante a busca pelo 
conhecimento; coerência e seriedade; o comprometimento e a qualidade no processo de formação inicial; e defender um currículo que além da teoria, atenda a prática docente e que contenha conteúdo específico dos conhecimentos geográficos. Para Nóvoa (1992, p. 81):

\begin{abstract}
É preciso reconhecer as deficiências científicas e a pobreza conceptual dos programas atuais de formação de professores e situar a nossa reflexão para além das clivagens tradicionais (componente científica versus componente pedagógica, disciplinas teóricas versus disciplinas metodológicas, etc.), sugerindo novas maneiras de pensar a problemática da formação de professores.
\end{abstract}

Portanto, uma boa formação inicial alicerça teórica e metodologicamente a trajetória do professor, para isso a instituição de nível superior precisa oferecer meios para a construção de conhecimentos. Segundo Cunha (2010, p. 149):

\begin{abstract}
São necessárias mudanças que promovam a ampliação e o aprofundamento nos campos da ciência, da arte e da técnica, sem desconhecer que é fundamental tratar, também, dos aspectos epistemo-metodológicos que envolvem as relações entre prática e teoria, a introdução de perspectivas interdisciplinares, a promoção do pensamento crítico, a criatividade, a capacidade de resolver problemas, de unir ensino e pesquisa como indicadores de melhoria da qualidade do ensino superior.
\end{abstract}

Diante disso, percebe-se que as considerações dos professores entrevistados, reforçam os argumentos expostos pelos autores e conduzem à reflexão quanto a importância do método de ensino, das práticas pedagógicas e dos conteúdos geográficos propostos como uma nova visão na forma de ensinar e de aprender. De acordo com Nóvoa (1992, p. 91), “As práticas e as formações tomam como referência as dimensões coletivas as quais contribuem para a emancipação profissional e para a consolidação de uma profissão que é autônoma na produção dos seus saberes e dos seus valores".

A partir daí, é possível a repensar a formação inicial, quanto a importância dos saberes docentes e de se fomentar práticas educativas para a melhoria da qualidade do ensino.

Quanto a dimensão da formação continuada, ela é, de certa forma, uma iniciativa do próprio profissional, mas necessária para a consolidação do exercício docente. A formação continuada deve ser desenvolvida, também, com o apoio das instituições educacionais nas quais os docentes atuam, tanto da pública quanto da privada. Segundo Nóvoa", "Ninguém forma ninguém, cada um, forma a si próprio". Continua o autor na mesma entrevista: “A formação é sempre um processo de transformação

\footnotetext{
${ }^{1}$ Entrevista ao Centro de Referência em Educação - CRE da Secretaria de Estado de Educação/SP, 2004.
} 
individual, na tripla dimensão do saber, do saber fazer e do saber ser”. Assim, o processo de formação é permanente e indissociável de uma concepção inacabada do ser humano.

Logo, o processo de formação do professor deve ser um ato contínuo para o seu desenvolvimento intelectual e profissional. No que concerne à formação do professor de Geografia, Neto e Silva (2019, p. 344) asseguram que: “deve estar incorporada ao seu arcabouço teóricometodológico no intuito de muni-lo para mobilizar os conhecimentos da ciência, do pedagógico e do contexto dos alunos".

No que se refere à formação continuada do professor com vistas ao seu aprimoramento, um dos professores entrevistados, em seu relato, argumentou: "as coordenações pedagógicas dos professores da escola pública, são espaços com potencialidades para o desenvolvimento da formação continuada e, nos momentos de reuniões coletivas, pode-se realizar atividades destinadas à qualificação e ao planejamento pedagógico".

De acordo com Schön (1990), o diálogo entre os professores é fundamental para consolidar saberes emergentes da prática profissional. São nos momentos das coordenações que o diálogo se estabelece e constitui-se em dispositivo relevante no desencadeamento das mudanças para a melhoria da prática pedagógica, para favorecer a inovação metodológica, para promover discussões teóricas, além de permitir aos professores aperfeiçoar os conhecimentos e compartilhar experiências ligadas à docência.

Portanto, as coordenações pedagógicas favorecem a realização de discussões coletivas, oportunizam a reflexão e a intervenção na prática docente concreta. Nesse sentido, os encontros coletivos possibilitam a busca por aprendizagens das bases teóricas e documentos oficiais; o debate relacionado às particularidades da escola como, por exemplo, o Projeto Político Pedagógico (PPP) com a finalidade de melhorar toda dinâmica desenvolvida pelo docente em regência de classe. Para McBride (1989), um grande desafio na formação de professores, consiste em reconhecer a escola como um ambiente educativo, onde trabalhar e formar não sejam atividades distintas. Dessa forma, a formação continuada, deve ser encarada pelo professor, como um processo contínuo e imprescindível, integrado ao dia a dia dos professores e da escola.

Além da formação, as experiências vivenciadas em sala de aula também favorecem para o exercício docente, porque permitem um processo permanente de reflexão de sua própria prática educativa, a qual é aperfeiçoada no decorrer dos anos de profissão. Para Neto e Silva (2019, p. 329), A docência é uma tarefa desafiadora, todavia, que pode ser alcançada por meio de estratégias 
renovadas e empenhadas para sua realização, obtendo-se assim, resultados relevantes de aprendizagem que sejam significativos para a vida do educando.

A experiência é também um saber docente e que ganha importância na formação dos professores, a partir do entendimento de que ela permite processos de reflexão das próprias práticas (PIMENTA, 2012). É por meio da experiência e da formação que a prática docente se solidifica refletindo assim no desempenho exitoso do profissional no seu cotidiano escolar.

\section{CONTRIBUIÇÕES DO GRUPO DE PESQUISA GEAF-UNB}

O Grupo de pesquisa GEAF-UNB foi formado no ano 2016, é ligado ao Departamento de Geografia da Universidade de Brasília $(\mathrm{UnB})$ e possui como área predominante de pesquisa as Ciências Humanas, especificamente, a Geografia Escolar.

Atualmente o grupo de pesquisa é constituído por profissionais da educação com as seguintes características: professores que ministram aulas no ensino fundamental e médio em escolas da rede pública e privada do Distrito Federal; professores que trabalham na formação inicial do curso de Geografia, da Universidade Aberta do Brasil - UAB/UNB, na modalidade EAD (Educação a distância); especialistas; mestre, doutores e, também, mestrandos e doutorandos da Universidade de Brasília (UnB).

As atividades desenvolvidas pelo grupo contemplam suas linhas de pesquisa, quais sejam: cartografia escolar e linguagens; dinâmicas físicas da Geografia e ensino-aprendizagem; educação no/do campo, indígena e subjetividade em Geografia; ensino-aprendizagem em Geografia; e formação inicial e continuada de professores de Geografia. Dentre os participantes, alguns estão em início de carreira e outros possuem experiência de mais de vinte anos trabalhando com a Educação Básica. Esses professores aceitaram participar da pesquisa, dispondo-se a pautar suas considerações e informações sobre seu trabalho e seus saberes.

O Grupo de pesquisa GEAF/UNB é um modelo de formação continuada constituído por professores/pesquisadores, os encontros possibilitam momentos de reflexão e oportunizam o docente a estudar e a repensar as suas práticas de ensino. As considerações feitas pelos professores entrevistados mostram que as reuniões são significativas e ajudam a: refletir, a partir das leituras, quanto a sua identidade profissional; compreender a importância do contexto social no qual o estudante está inserido; entender o significado do currículo para a construção das aprendizagens; e 
ampliar a visão relacionada à importância da autonomia pedagógica para a promoção do ensino da ciência geográfica.

As entrevistas com os membros do GEAF-UnB apontaram que eles consideram os estudos dos textos pertinentes à aproximação com os autores da Geografia escolar e que este contato é fundamental para a prática docente. Além disso, segundo os professores participantes, os encontros em ambiente acadêmico são motivadores, por agregar profissionais interessados em estudar e pesquisar.

Para os entrevistados, o professor, independente da fase da sua carreira, precisa repensar o seu perfil de educador e estar aberto à reestruturação de propostas pedagógicas inovadoras como, por exemplo, o uso das TICs (Tecnologias de Informações e Comunicação), tal proposta pode ser estratégica para o ensino geográfico. Nóvoa (1992, p. 81) destaca que: “A formação passa pela experimentação, pela inovação, pelo ensaio de novos modos de trabalho pedagógico e por uma reflexão crítica sobre a sua utilização".

No entanto, a trajetória do professor de Geografia se complementa com a formação continuada, que discute demandas da formação, dos conhecimentos e dos conceitos geográficos fundamentais que, em algum momento, ficaram adormecidos. No entanto, compartilhar experiências também é aprendizagem e fundamenta o saber docente. Segundo Nóvoa (1992, p. 14):

O diálogo entre os professores é fundamental para consolidar saberes emergentes da prática profissional. Os problemas da prática profissional docente não são meramente instrumentais; todos eles comportam situações problemáticas que obrigam a decisões em um terreno de grande complexidade, incerteza, singularidade e de conflito de valores.

Portanto, ao compartilhar de experiências e participar de grupos de estudos e de pesquisa, os professores têm a oportunidade de construir a identidade docente, compreender o significado social da profissão e refletir sobre o modo como se ensina e desenvolve a prática docente no cotidiano escolar.

\section{RESULTADOS E REFLEXÕES}

A partir do resultado das análises dos relatos dos professores a respeito da formação, constatou-se ser necessário avanços, uma vez que muitos professores vão para a sala de aula sem o preparo adequado para exercer a profissão e o domínio da docência vai sendo conquistado com a 
experiência construída em sala de aula, mas, vai deixando lacunas, muitas vezes irreparáveis. Cavalcanti destaca que:

[...] a formação do professor deve ter como meta a conquista de sua autonomia intelectual e o desenvolvimento da capacidade de articulação das contribuições teóricas da área com as atividades profissionais cotidianas. Essa autonomia do professor provê condições de pensar a prática, de questionar a realidade profissional, de tomar decisões e de, enfim, organizar as atividades rotineiras (2017, p. 102).

Para evitar que as lacunas se estabeleçam no decorrer do desenvolvimento profissional do docente, aliados à experiência, a autonomia intelectual e as contribuições teóricas, também são necessários os saberes pedagógicos e do conhecimento, dentre outros, que exigem estudos mais detalhados.

Segundo os entrevistados, é fundamental formar profissionais capazes de promover práticas pedagógicas motivadoras para a construção do conhecimento geográfico. $\mathrm{Na}$ compreensão de Cavalcanti $(2017$, p. 23) o conhecimento geográfico significa "[...] conhecer e refletir sobre sua estrutura analítica (princípios, categorias, conceitos, teorias) sobre a trajetória desse ramo do conhecimento, e sobre suas principais formulações e seus avanços atuais”.

O entendimento de que os sabedores docentes da experiência, do conhecimento e pedagógico se complementam e devem fazer parte da formação dos professores é reforçado pela ideia de Pimenta (2012, p. 26) a qual argumenta que "[...] para saber ensinar não bastam a experiência e os conhecimentos específicos, mas se fazem necessários os saberes pedagógicos e didáticos”.

Os entrevistados também apontaram que as instituições de ensino superior devem formar professores com viés de pesquisador, construtores de saberes essenciais para a prática educativa de qualidade. Segundo um entrevistado, “o professor pesquisador tem visão de mundo mais ampla em relação às temáticas geográficas”. Com isso, promover a interação entre a teoria e a prática, contribui para a habilidade docente de realizar ações pedagógicas mais dinâmicas para o desenvolvimento dos saberes do conhecimento, e este não se reduz a informação (MORIN, 1993), conhecer implica trabalhar com as informações, classificando-as, analisando-as e contextualizando-as (PIMENTA, 2012).

Quanto ao resultado das análises dos relatos referentes à formação continuada, os entrevistados declararam que ela depende, também, do interesse pessoal do professor. Segundo Pimenta (2012, p. 32), “a formação é, na verdade autoformação, uma vez que os professores 
reelaboram os saberes iniciais em confronto com suas experiências práticas, cotidianamente vivenciadas nos contextos escolares". Logo, a formação é necessária para que o docente compreenda melhor a realidade na qual os seus alunos estão inseridos. Com isso, a capacitação pode beneficiar o trabalho docente, permitindo ao professor superar as dificuldades enfrentadas no cotidiano da sala de aula que interferem no seu desempenho profissional.

Os professores que participaram da pesquisa, consideram que as coordenações pedagógicas são importantes para que se possa discutir os problemas que afetam as práticas docentes e que favorecem para as trocas de experiências. Além disso, esses momentos devem ser utilizados para estudos diversos relacionados à educação.

No que diz respeito ao sentimento de identidade do professor em relação à sua profissão, os autores que contribuíram com o aporte teórico e os entrevistados entendem que a qualidade tanto da formação inicial quanto da instituição superior onde concluíram o curso, são essenciais para a formação do docente pois,

Para além da finalidade de conferir uma habilitação legal ao exercício profissional da docência, do curso de formação inicial se espera que forme o professor ou que colabore para a sua formação. Melhor seria dizer que colabore para o exercício de sua atividade docente, uma vez que professorar não é uma atividade burocrática para a qual se adquire conhecimentos e habilidades técnico-mecânicas (PIMENTA, 2012, p. 18).

Assim, a formação inicial que valoriza o conhecimento teórico da educação e os saberes pedagógicos necessários à compreensão do ensino como realidade (PIMENTA, 2012), refletem na trajetória profissional docente e na construção da identidade como professor.

Outros elementos necessários para a identidade docente são as trocas de experiências entre os pares e as reflexões quanto ao significado social de ser professor. Segundo Pimenta (2012, p. 20):

Uma identidade profissional se constrói, pois, a partir da significação social da profissão; da revisão constante dos significados sociais da profissão; da revisão das tradições. Mas também da reafirmação de práticas consagradas culturalmente e que permanecem significativas [...].

O docente que se identifica com a profissão estará na busca constante do aprender e do aprimoramento para ensinar. A análise dos relatos dos professores participantes da pesquisa mostrou que as discussões apresentadas no artigo são importantes e necessárias para o professor de Geografia que está atuando na Educação Básica, uma vez que essas discussões problematizam e despertam nos 
envolvidos a capacidade de estudar e questionar temáticas relacionadas ao ensino de Geografia, as ações pedagógicas e a formação docente.

\section{CONSIDERAÇÕES FINAIS}

Mediante os resultados apresentados, verifica-se que a formação inicial e a continuada de professores constituem-se em processos que favorecem o desenvolvimento profissional, dá ao professor a autonomia intelectual, eleva perspectiva de sua trajetória, não de forma linear, mas, como um crescimento progressivo e em sintonia com as suas experiências e vivências.

Os conhecimentos adquiridos na formação inicial já não suficientes para o exercício da docência com qualidade. Logo, torna-se indispensável a formação continuada do professor para acompanhar as mudanças constantes pelas quais o mundo passa, estando assim habilitado para ensinar de forma reflexiva, autônoma e responsável, por meio de práticas educativas motivadoras favoráveis ao desenvolvimento da aprendizagem e da pesquisa em Geografia.

É importante ressaltar que a partir das inferências expostas, cada professor atribui valor à sua formação e qualificação na busca da autonomia intelectual. Essa autonomia permite ao professor reconhecer o poder transformador que tem enquanto produtor de saberes e de conhecimento.

Portanto, o professor precisa se identificar com o trabalho que realiza, conhecer os saberes e sua capacidade de produzi-los em sala de aula. Os saberes da experiência, do conhecimento e o saber pedagógico são conquistados por meio de uma boa formação inicial, de uma capacitação constante que se adquire na prática cotidiana na rotina escolar, na troca de experiências durante estudos e reuniões pedagógicas e, também, realizando cursos relacionados à docência. É por meio da formação que o profissional alcança a autonomia e a liberdade para a prática docente, esses elementos são imprescindíveis para o ensino de Geografia de qualidade

Embora existam políticas voltadas à formação de professores no Brasil, elas ainda apresentam fragilidades e necessitam de mais investimentos, tanto para a formação inicial quanto para a continuada. A formação docente de qualidade, pode favorecer o ensino de Geografia na Educação Básica, de maneira que o aprendizado se concretize efetivamente.

\section{REFERÊNCIAS}


BAUER, Martin W.; GASKELL, George. (org.). Pesquisa qualitativa com texto, imagem e som. $13^{\mathrm{a}}$ ed. Petrópolis, RJ: Vozes, 2017 (reim.).

BRASIL, Lei de Diretrizes e Bases da Educação Nacional. Lei nº 9.394/96, de 20 de dezembro de 1996.

CAVALCANTI, Lana de S. O trabalho do professor de Geografia e tensões entre demandas de formação e do cotidiano escolar. In. ROQUE, V de O. Ascenção... [et. Al.] (Orgs.) Conhecimentos da Geografia: percursos de formação docente e práticas na educação básica. Belo Horizonte: IGC, 2017.

CAVALCANTI, Lana de S. Ensino de Geografia e demandas contemporâneas: práticas e formação docente. In: ALVES, A. O.; KHAOULE, A. M. K. (Orgs.) Fundamentos teóricos na formação do professor de Geografia. C\&A Alfa \& comunicação, Goiânia, 2017.

CUNHA, M. I. Lugares de formação: tensões entre a academia e o trabalho docente. In: DALBEN, A.; LEAL, L.; SANTOS, L (Orgs.). Convergências e tensões no campo da formação e do trabalho docente: didática, formação de professores, trabalho docente. Belo Horizonte: Autêntica, 2010. p. 129-149.

DALFOVO, Michael Samir; LANA, Rogério Adilson; SILVEIRA, Amélia. Métodos quantitativos e qualitativos: um resgate teórico. Revista Interdisciplinar Científica Aplicada, Blumenau, v. 2, n. 4, p. 01-13, Sem II, 2008. ISSN 1980-7031

NETO, Daniel R. S.; SILVA, Juanice P. S. O raciocínio geográfico de alunos com deficiência intelectual em uma escola pública do Gama-DF. Terra Livre, v. 2, n. 53, p. 318348, jul-dez. 2019.

MCBRIDE, Rob (ed.). The In-Service Training of Teachers. Lewes: The Falmer Press, 1989.

MORIN, Edgar. Toffler e Morin debatem sociedade pós-industrial. Folha de S. Paulo, 12 dez. 1993, supl. World Media.

NÓVOA, Antônio. Os professores e sua formação. Lisboa: Dom Quixote.1992.

Educação e formação ao longo da vida. CRE Mário Covas/SEE, SP. Entrevista concedida por e-mail em outubro de 2004 ao CRE Mario Covas/SEE-SP. Disponível em: http://www.crmariocovas.sp.gov.br/

PICONEZ, Stela. (Coord.) A prática de ensino e o estágio supervisionado. Campinas, Papirus, 1991.

PIMENTA, Selma Garrido. Formação de professores: identidades e saberes da docência. In: PIMENTA, Selma Garrido. (Org.). Saberes pedagógicos e atividade docente. São Paulo: Cortez Editora, 2012. 
SCHÖN, Donald A. (1990). Formar professores como profissionais reflexivos. In: NÓVOA, A. (coord.). Os professores e sua formação. Lisboa: Publicações Dom Quixote, p. 77-91.

SILVA, S. A. R. \& BARBOSA. J. R. A. Formação Continuada de Professores para a Atualidade: Tecendo relações, trajetórias e desafios entre Universidade e Escola. In: FERREIRA, Gabriella R. (Org.). Formação Docente nas Dimensões Ética, Estética e Política 2. [Recurso eletrônico]. Ponta Grossa, PR. Ed. Atena, 2019. p. 140 - 148.

SHULMAN, Lee S. Conocimiento y enseñanza: fundamentos de la nueva reforma. Profesorado. Revista de Currículum y Formación de Professorado. v.9, n.2, Granada, España, 2005. 